\title{
Dinâmica da modernidade na América Latina: sociabilidades e institucionalização
}

\author{
Carlos Gadea
}

\section{Qual modernidade?}

A possibilidade de se perguntar sobre a condição histórica da modernidade na América Latina não tem deixado de inquietar a todos aqueles vinculados com as diferentes esferas da cultura. Diversas interpretaçôes têm surgido, geralmente associadas às aventuras políticas, os diferentes processos de modernização econômica e as mudanças nas formas de observar o devir cultural e suas formaçôes conseqüentes. $\mathrm{O}$ que aqui se pretende é reintroduzir o debate sobre a modernidade na América Latina, reconsiderando e reavaliando aquele iniciado em fins dos anos 1980 e começo dos 1990, visivelmente negligenciado, por exemplo, a partir do surgimento do debate sobre a globalização e os seus desdobramentos econômicos e socioculturais. Uma espécie de neo-economicismo, que especulava acerca das desventuras latino-americanas em torno das chamadas políticas neoliberais, provocou a paulatina saída da cena de diversos pensadores e uma virada nas iniciativas de pesquisa. Como conseqüência, as reflexōes e discussōes que se herdaram impediram a tentativa por reconsiderar (a partir de uma multiplicidade de perspectivas) as construçóes históricas e discursivas sobre a modernidade e a análise da eventual crise das suas conotações normativas, políticas e sociais.

A idéia de fundo é enfatizar que uma análise da modernidade na América Latina sugere destacar aqueles dispositivos normativos que se referem à formalização e institucionalização de experiências sociais e culturais. A modernidade apareceria, assim, como uma categoria claramente definível devido ao produto de uma construção sociológica baseada na clássica dicotomia entre modernidade e tradição. Entretanto, alguns autores sugerem que:

Habría que partir, por ejemplo, por entender el contexto operativo de la cultura que suele llamarse tradicional (y en algunos países, oligárquica), si 
se desea luego abordar el análisis de las rupturas y continuidades que implica la emergencia de la modernidad latinoamericana. (Brunner; 1992, 43)

A análise aqui assumida requer relativizar todo esforço por compreender o moderno como síntese histórica substitutiva do tradicional. Essa dicotomia pode operar como "tipo ideal" para, justamente, diferençar inter-relaçóes sociais e seus contextos de produção e representação, porém não para sugerir etapas de uma evolução histórica. Não se trata de etapas ou estágios históricos "objetivos", da passagem de "mundos materiais e simbólicos" de menor grau de complexidade para outros de complexidade maior (tradição-modernidade e, eventualmente, pós-modernidade), ou do advento ou emergência de uma condição social e cultural que acabaria substituindo uma anterior. Na América Latina, "o moderno" se rodeia de uma nebulosa cultural e social nem sequer facilmente constatável quando é confrontada com "seu outro": a tradição. Neste sentido, é possível deduzir que esta falsa dicotomia conduz uma identificação pouco evidente do moderno, uma espécie de hibridação das experiências e práticas sociais definidora de uma ausência daquilo propriamente moderno ou tradicional. Tradição e modernidade, como bem constata Richard (1993, 373), deixam de contrapor-se sob o signo da ruptura do antagonismo entre o velho e o novo: a modernidade não chega para substituir a tradição, mas para misturar-se com ela.

Não existe uma linha de evolução imutável da modernidade, um acontecer histórico a priori delimitado por determinadas forças ideológicas, políticas e institucionais. Por isso, o desenvolvimento da modernidade na América Latina em absoluto supõe uma repetição destemporalizada de uma suposta modernidade gerada na Europa ou nos Estados Unidos. Quando se fala, por exemplo, de graus de institucionalização e formalização da vida social deve ser levado em consideração que têm sido, e continuam sendo, processos que conciliam cadeias de interação social particulares de acordo aos graus diversos de contingência apresentados. Pode supor-se, então, que é possível compreender a existência de uma "particular" modernidade na América Latina? Obviamente que não. Nem particularidade, que significaria uma representação equivocada de um processo histórico geral, no qual a Europa e a América Latina se constituem em evidente inter-relação, e muito menos a repetição ou transferência linear 
de "uma realidade" e seus marcos institucionais para "uma realização" e suas adaptaçôes de ordenamento normativo em um contexto alheio.

$\mathrm{O}$ que interessa observar na modernidade latino-americana são aqueles dispositivos normativos que impóem (ou pretendem impor) uma determinada ordem sociocultural. $\mathrm{O}$ moderno parece adquirir seu locus constitutivo e sua mais concreta materialização num processo de universalização de normas, generalização de valores e formalização das interações sociais, considerando que: enquanto se produz uma maior integração na lógica institucional, mais se padronizam as práticas sociais e se introduzem novas limitações a respeito das atividades, ações e identidades permitidas e eventualmente válidas e legítimas.

Os processos históricos independentistas e seus anseios por uma ordem liberal, as posteriores narrativas nacionalistas e românticas de fins do século XIX e início do XX, os costumes e rituais cotidianos próprios do disciplinamento e da racionalização, o controle da sexualidade, a escola, o médico, os presídios; tudo isso pode ser entendido dentro de iniciativas políticas, culturais e econômicas cujo grande relato legitimador descansa nos fundamentos epistemológicos do projeto histórico clássico da modernidade: indivíduo, ordem, progresso e desenvolvimento. Na América Latina, este se inicia e se consolida com a industrialização massiva, a urbanização em grande escala e os diferentes dispositivos de racionalização da vida cotidiana. A "domesticação dos instintos", a sujeição das vontades individuais, a canalização de desejos pessoais para fins gerais e o disciplinamento de ambições em função de objetivos sociais que se materializaram com os estatutos jurídico-institucionais e a regulação e o controle social são alguns exemplos disso (Mansilla, 1992). Ainda que seja uma questão altamente especulativa, referir-se ao moderno no heterogêneo contexto latino-americano sugere destacar aqueles processos que fazem referência ao disciplinamento, ${ }^{1}$ a formalização, a uniformização e a institucionalização ${ }^{2}$ de experiências sociais, culturais, políticas.

\section{Modernidade e sociabilidade}

Como analisou o historiador José Pedro Barrán (1990, tomo II), a "nova sensibilidade civilizada" supôs um sistema de controle social, de vigilância e de construção de civilidade em que as instituiçóes como o pro- 
fessor, o médico, o sacerdote e o Estado cumpriram papéis fundamentais. Fica difícil dissociar esses sujeitos sociais, figuras culturais ou instituições uns dos outros, na medida em que atuaram, desde o começo do século XX na América Latina como os portadores dos preceitos modernizadores e modernistas na cultura, nos costumes e gostos. Assim, é possível estabelecer a trilogia conceitual que caracterizaria a modernidade latino-americana: modernização que se originaria por meio dessas instituições e que aspirariam a uma universalização dos preceitos políticos, morais e socioculturais.

Nenhuma suposta "ordem" pré-moderna poderia "integrar" e vincular aqueles homens e mulheres latino-americanos do final do século XIX e começo do século XX. Logo após as variadas lutas regionais, políticas, religiosas e de "modelos identitários" sobre as idéias relativas à construção de uma nação, o peso sobre a consolidação de uma determinada "ordem" da sociedade recairia em instituiçốes especializadas funcionalmente (instituiçôes políticas, educativas, de higiene e saúde, econômicas e jurídicas) ${ }^{3}$. A partir disso, foi uma ambígua lógica institucionalizadora que se expressou na América Latina. Ambígua porque se caracteriza por seus marcados signos de fragilidade e ausência em determinadas esferas da vida social ${ }^{4}$ e, ao mesmo tempo, por sua forte presença uniformizadora materializada em uma instituição acima das demais. Uma instituição estabeleceu hierarquias em todas elas, as absorveu e as assimilou como próprias de sua dinâmica e influência, adquirindo, pelo mesmo gesto, uma diversificação e pluralidade em suas funções. As funções políticas, jurídico-morais, entre outras, adquirem um lugar de hierarquia institucional concentradas na figura do Estado. É dessa maneira que a ordem social moderna se fazia diferente da piramidal dinâmica pré-moderna; em parte, claro. Na América Latina, esse desenlace ordenador e organizador da vida sociocultural consegue definir a "sua modernidade" como um produto histórico que não esquece que foi precedida por uma "outra ordem" identificada com a injustiça, o subdesenvolvimento, a pobreza, a violência e a heterogeneidade, com uma "ordem caótica". A "natureza”, sinônimo de desordem, era finalmente vencida. Era a diferença ordenada hierarquicamente do pluriverso pré-moderno na América Latina a que foi finalmente vencida. Em conclusão, um específico "mapa” hierárquico é o que desapareceria e, eventualmente, seria substituído. Dentro da ordem moderna, ${ }^{5}$ a hierarquia social se estabelece no nível das instituiçõos especializadas. 
As práticas sociais ou sociabilidades formavam uma aparente ordem articulada, ou ao menos era o que se pretendia. A específica modernidade latino-americana partia da idéia de que a pluralidade e diversidade das sociabilidades dificultava a tarefa de imaginar-se um ator supostamente coletivo, capaz de intervir em nome e a favor de idéias universalistas. Dotado de uma alta razão histórica e de uma vontade unitária, uniformizadora e homogeneizadora, o Estado será esse ator portador de coesão e coerência das práticas perfeitamente organizadas e crescentemente institucionalizadas. Estado e direito materializariam o poder disciplinador, levando-se em conta que o direito é, antes de tudo, um "princípio de racionalidade". No entanto, além de encarnar um conjunto de regras pretensamente universais e abstratas que circunscrevem o poder e o Estado, o direito não existe enquanto tal. $\mathrm{O}$ que existem são práticas jurídicas que se referem a um específico "princípio de racionalidade". Esse princípio é o que ordena as práticas legislativas, as doutrinas, a jurisprudência, a aplicação e distribuição de justiça (Ewald, 1993).

\section{Sociabilidades e institucionalização}

As instituições de um mundo moderno implicam a historicidade e o controle. Daí que resulte impossível compreender as lógicas institucionais na América Latina sem considerar o complexo processo histórico em que têm sido produzidas. Pode-se deduzir, por conseguinte, que as diferentes histórias consagradas têm sempre situado a dinâmica da modernidade sob o fogo cruzado do disciplinamento, por um lado, e a liberação das ataduras pré-hispânicas, coloniais e comunitárias, por outro. Ainda que sejam reconhecidas as histórias de liberação que acompanharam a dinâmica da modernidade, a lógica disciplinar e uniformizadora estabeleceu-se, também, em fator constitutivo dela. As instituições, pelo simples fato de reger a vida coletiva, controlam a conduta, estabelecendo padrôes previamente definidos e canalizando-a numa direção específica. Este caráter controlador (e disciplinador) é inerente à institucionalização enquanto tal. Dessa forma, afirmar que uma concreta atividade individual ou coletiva (política, sexual etc.) foi institucionalizada, representa afirmar que tem sido finalmente submetida ao controle social (Berger \& Luckmann, 2001). 
Com o tempo, a objetividade do mundo institucional se expressa como uma realidade dada, como um mundo que se torna "o mundo". Ao tornar-se "real" de maneira mais sólida, já não parece poder ser transformado com tanta facilidade. A flexibilidade não é uma característica que se faça visível para todos. Ao contrário, o mundo institucional transmitido nos processos de socialização não é completamente transparente, já que, ao não participar na formação dele, a muitos se apresenta como uma "realidade objetiva”, dada, evidente e inalterável. Para amplas camadas da população latino-americana, do meio rural inóspito e longínquo até o anonimato suburbano das grandes cidades, as instituições se percebem como "realidade exterior", ainda que gradualmente interiorizadas em seus cotidianos. Têm um poder coercitivo, dado o poder dos mecanismos implícitos de controle e disciplinamento. Não obstante, o mundo institucional exige legitimação, isto é, modos pelos quais pode ser explicada e justificada sua funcionalidade. Isso se deve ao fato que a realidade do mundo social que encarna é histórica, fazendo com que as novas gerações tomem contato com ele como tradição e não como memória de vida. Aqui é onde radica, primeiramente, um problema de legitimação que faz da variável temporal um fator criticamente pós-moderno. Por quê? Porque o conhecimento que se adquire da história institucional específica é recebido por uma "transmissão oral" das gerações mais velhas. Torna-se imprescindível, então, interpretar para as geraçôes mais jovens o significado original das instituições em várias fórmulas legitimadoras. Estas teriam de ser suficientemente convincentes no que se refere à ordem institucional para que as gerações de jovens sejam convencidas. É esse distanciamento gradual dos elementos fundadores do mundo institucional o que estaria gerando a crise própria da dinâmica da modernidade latino-americana. É, assim mesmo, a aparente dificuldade das diferentes linguagens legitimadoras serem "apreendidas" pelas novas geraçôes (durante o mesmo processo que as socializa na ordem institucional) a que se refere a sociabilidade que escapam à dinâmica da modernidade.

Porém, na América Latina, o desenvolvimento de mecanismos concretos de disciplinamento e controle social tem conseguido tornar-se necessário com a objetivação das instituições. Tem-se recorrido sempre a elas para superar eventuais crises que, em muitas ocasióes, eram próprias de sua inadequada funcionalidade e "artificialidade" em um determinado con- 
texto sociocultural. Rapidamente, se as instituições passavam a ser realidades divorciadas de seu fundamento original nos processos sociais dos quais surgiam, estabelecia-se uma série de sanções correspondentes para aqueles que as transgrediam de alguma forma, já que as instituições pretendem ter autoridade sobre os indivíduos, independentemente dos significados particulares que eles possam atribuir a qualquer situação concreta. A prioridade das definições institucionais das situações era coerentemente preservada das críticas, transgressões e tentações individuais de redefinição.

O problema acerca da capacidade de redefinição do mundo institucional radica no campo de sua legitimação. Deve-se estar de acordo que o compêndio de legitimaçôes é construído sobre a linguagem, sendo usado, em teoria, como seu principal instrumento. Assim, a dinâmica atribuída à ordem institucional forma parte do acervo histórico e socialmente disponível de conhecimento. Isso se relaciona à idéia de que a transmissão do sentido e significado de uma instituição se baseia no seu reconhecimento social como solução potencialmente permanente de um problema também permanente de "uma ordem social específica". Os potenciais atores sociais de ações institucionalizadas devem tomar conhecimento desses significados, supondo, conseqüentemente, alguma forma de processo educativo, o que em muitas ocasiōes se tem entendido como sinônimo de uma "ampliação da cidadania". Embora sejam questôes bastante diferentes, e que se referem a esferas semânticas distintas, podem ser correspondentes a uma tentativa de conseguir legitimações apropriadas para um determinado mundo institucional eventualmente ferido de legitimação. Vai se encontrar na "multiplicidade" de linguagens legitimadoras do mundo institucional, da fragmentação social (como alguns gostam de dizer) conseqüente, o problema mais sério para uma dinâmica da modernidade que encarna a necessidade de integração institucional para as diversas sociabilidades a partir de um universo de significações socialmente compartilhado.

\section{Institucionalização e normatividade}

A dinâmica da modernidade na América Latina não reconheceu limites culturais e políticos para sua contínua reafirmação. ${ }^{6}$ Quando algo se interpunha, o combatia diretamente por meio da violência (como com as culturas indígenas, ainda que não sempre triunfante), ou tentava absorvê- 
lo sob seus postulados de futuro ordenamento social. As múltiplas práticas modernizadoras não reconheciam a priori limites que tentaram frear seu embalo. Caso existissem, os transcendia. Desafiavam continuamente a legitimidade das instituiçôes, as criticavam e as rechaçavam. Questionando tudo, não destruíam, mas mantinham a suposta "ordem moderna".

Porém, na América Latina, não é possível referir-se a uma específica "ordem moderna". Torna-se mais apropriado referir-se a uma "dinâmica da modernidade", a uma série de regras que vão se apresentando em contextos e temporalidades diversas em prol de uma "eventual ordem" que estaria por apresentar-se logo depois da prolongada luta contra os vestígios de laços pré-modernos que atentam contra o desenvolvimento social e o progresso moral. Sem uma específica "ordem", a sociabilidade latino-americana se apresenta sempre ante um espelho que devolve imagens contraditórias, incertas e mutáveis. A idéia de dinâmica sugere esta inacabada sensação de estar em uma ordem social que, existindo, pretende-se alcançar. Dinâmica e ordem entram em um jogo dialético.

É na América Latina onde mais se pode afirmar que o termo "projeto da modernidade" não é de todo apropriado. Um projeto pode ser levado adiante de diversas formas, existindo, assim mesmo, um ponto em que é possível dizer-se que foi concluído. Nesse sentido, a modernidade não é um projeto (Heller \& Fehér; 1994, 139). Suas categorias estão em um estado de atividade constante.

Habermas menciona el proyecto inacabado de la modernidad. Esta es una buena expresión si añadimos que el proyecto nunca se acabará, porque acabarlo significa matarlo. La modernidad [...] puede asumir variaciones prácticamente infinitas al igual que la pre-modernidad, pero su dinamis las incluyen a todas in nuce (Ibid).

Assim parece manifestar-se nas práticas sociais historicamente desenvolvidas na heterogênea América Latina. As "variações praticamente infinitas" que pode assumir a dinâmica da modernidade podem distinguirse em diferentes experiências culturais sedimentadas, que têm coberto o cenário latino-americano com um manto diverso de práticas políticas e sociais em absoluta convivência, pujança e luta: por exemplo, o que corresponde ao universo da religião, das culturas indígenas, das diversas 
manifestaçōes afro-americanas, do "mundo bárbaro" associado ao espaço rural, das estruturas políticas "clientelistas" herdeiras de práticas "nãomodernizadas", entre outras.

Além de a lógica institucional latino-americana pretender abolir as diferenciações culturalmente surgidas no mesmo processo da dinâmica da modernidade, a expansão da "formalização" das sociabilidades teria de lidar com uma multiplicidade de maneiras de levar adiante a própria institucionalização. A diversidade cultural ou a "multiplicidade de linguagens" que historicamente seriam transformadas ou simplesmente questionadas pelo desenvolvimento da modernidade em todo momento geraram mecanismos de tensão suficientemente fortes como para transgredir, criticar e questionar, reiteradamente, a lógica institucional implantada por uma elite intelectualmente preparada e politicamente educada para tais finalidades. Uma ampla gama de movimentos e atores sociais assim o tem evidenciado, como ultimamente o tem registrado o desdobramento mobilizatório e discursivo do movimento indígena neozapatista do México.

Talvez seja uma lógica da contaminação, do conflito contínuo e de uma aspiração modernizadora, que isoladamente se propõe a uma tarefa enquanto consegue realizar outra, o que pode definir a dinâmica da modernidade na América Latina. Culturalmente, não há dúvidas disso. A referência ao hibridismo não é uma novidade a esta altura. A questão mais curiosa é a compreensão de uma específica "formalização" das ações cotidianas, das sociabilidades, como espécie de reinterpretação do mundo e de reclassificação de seus elementos com um olhar dirigido ao aumento da capacidade de controle e direção, de "destino" social e político. É nessa "formalização" que se apóia a conquista das instituições modernas no que se refere à aplicação de seu campo de ação (Wagner; 1997, 68).

$\mathrm{Na}$ América Latina, não em menor escala que nos contextos europeus e norte-americanos, o desenvolvimento de "formalizaçóes" das sociabilidades representou um determinado esquema classificatório, ordenador, redutor e de exclusão de maneiras de "estar no mundo". Isso é conseqüência, obviamente, da construção de conceitos ou categorias que representam uma realidade previamente interpretada do mundo social, pela qual se fixam normas de conduta inclusivas e excludentes, assim como se estruturam possibilidades de ação e o traçado de fronteiras do legítimo e do 
excluído - fronteiras no sentido de "convençôes sociais" criadas em condiçôes particulares, e também no sentido de "criar identidades" sociais que, com o tempo, se apresentaram para todos como "naturais". Resultará um gesto crítico a incredulidade nesta possibilidade de poder "criarse" um código ético não-ambivalente e sem contradições (Bauman; 1997, 15), isto é, um código classificatório do correto e do não-correto, de hierarquias de valor arbitrariamente postas na cena social.

Todavia, ao referir-se à institucionalização na América Latina, várias análises reiteram sua possibilidade à medida que ela seja regida e se materialize na esfera política, na órbita da legalidade e do direito, definitivamente, nos marcos jurídico-regulatórios da vida em sociedade. Pensa-se, por exemplo, no diagnóstico amplamente difundido da "baixa institucionalização" no contexto latino-americano devido à debilidade do direito e do constitucionalismo como instituiçōes (Peruzzotti, 2001):

¿Cuáles son las causas de la baja institucionalización en América Latina?[...] el bajo nivel en la construcción institucional exhibida por las sociedades latinoamericanas está íntimamente ligado a las formas asumidas en el proceso histórico de autoconstitución de sus sociedades civiles, más específicamente, con la erosión de los acuerdos legales constitucionales por parte de formas populistas de autoentendimiento (p.162).

Pode-se dizer que, em parte, é tudo isso certo. Em parte porque a suposta "precariedade institucional" diagnosticada não é tal se a entendemos como incapacidade de regular certos mecanismos de convivência sociocultural. Os valores e normas, gerados na mesma dinâmica de socialização, são adquiridos e fazem parte do meio social em que se apresentam. Da mesma maneira, sua institucionalização é também parte desse ambiente social, não sem resistências e contradições. O processo de institucionalização na América Latina corresponde a uma particular (ou a particulares) dinâmica sociocultural e aos acordos contingentes desenhados durante o mesmo processo de internalização de códigos coletivos e valores. A lógica institucional, atendendo inclusive às variadas formas de seu desenvolvimento, se materializou incorporando ou, melhor dito, com a co-participação daqueles elementos histórico-culturais, políticos e de valoraçôes definíveis como "exteriores" à dinâmica da modernidade. Todas 
as figuras definidas como "exteriores" a ela (supondo, desde já, um grande erro conceitual e metodológico), como poderiam ser o indígena, o negro, o "caciquismo", o clientelismo, o "apadrinhamento", figuras supostamente "pré-modernas", têm sido, e continuam sendo, protagonistas também centrais da particularidade da lógica institucional latino-americana. ${ }^{7}$ Essa característica, além de contradizer o diagnóstico da "precariedade institucional”, conduz a uma institucionalização ainda mais ampla (ainda que instável também), mais inalterável e crescentemente mais complexa e dinâmica. Não é que não exista institucionalização e "formalização" das sociabilidades e, por conseguinte, uma suposta coesão social, pela presença de práticas políticas e culturais como o "populismo" ou o autoritarismo. A lógica institucional na América Latina se caracteriza por ser produto das diferentes experiências culturais sedimentadas e da variedade de mecanismos e recursos sociais que lhe são próprias. Por isso, qualquer resposta à lógica institucional representa lidar com uma multiplicidade de loci culturais e éticos. As pressões normativas, no sentido de institucionalização de sociabilidades toleráveis e moralmente aceitas, parecem renderse a uma dinâmica da modernidade que, ao mesmo tempo, tem gerado a deslegitimação de seus próprios fundamentos. Uma suposta crise advém como conseqüência de mudanças nas regras, de inovações institucionais e, fundamentalmente, das transformações na própria configuração das instituições. Isso, sem dúvida, relaciona-se com a retórica legitimadora dos "laços modernos" em constante transformação, tal qual o menciona Lyotard (1989a) ao enfatizar as mudanças nos "estatutos do saber". Se os problemas se localizam no campo da legitimação, não há dúvida de que a lógica institucional latino-americana apresenta sintomas de crise.

Naqueles eventuais "modelos modernizadores” paradigmáticos, como pode ser o caso do Uruguai, nos quais a progressiva e exitosa secularização política e social do país (por exemplo, com a precoce separação da Igreja do Estado) supôs uma "alta institucionalização", os fatores de crise têm-se feito tão presentes como naqueles de suposta "baixa institucionalização". Se por modernização e desenvolvimento se compreende industrialização, o caso uruguaio denota um modelo no qual, no começo do século XX, 
la industria promovería la transformación de las arcaicas estructuras rurales, el mejoramiento de la distribución del ingreso, la modernización de la sociedad y el desarrollo de un sistema político armónico, en que el acuerdo social se derivaría de la articulación de productores y consumidores, de empresarios y asalariados, de un mercado nacional en expansión (Rama; 1987, 65).

O "mito" democratizador e igualitarista, gerador de uma ampla "classe média” no Uruguai, veio a tomar força e adquirir fundamento nesse processo de industrialização e conseqüente modernização da sociedade, ${ }^{8}$ "mito" que, por exemplo, serviu em seu momento para tomar distância do "modelo argentino", ao qual muitas vezes sentia-se dependente. $\mathrm{O}$ problema histórico da definição de uma identidade uruguaia qualitativamente diferente da Argentina (ao que tantos traços sociais se assemelham) pareceu resolver-se com uma auto-imagem na qual o "modelo modernizador" em curso se fundamentava sobre a base de uma forte integração nos valores democráticos, de exaltação das instituições e de um processo de integração social sem autoritarismo e populismos (ibid. 61). A paciente consolidação de uma sociedade presumivelmente moderna não poderia sentir-se melhor na primeira metade do século XX. Um Estado forte formou a sociedade de acordo com as prioridades de integração nacional, de institucionalização e de identificação entre sociedade e Estado através do processo político democrático. Ele significou uma negação por assumir os inevitáveis conflitos com os setores sociais mais "retardatários" e, no outro extremo, mais "críticos", já que ao fazê-lo teria de haver postergado a dinâmica de integração democrática e continuar uma direção do processo a partir de um Estado relativamente autônomo, com o risco iminente do autoritarismo político. Um amplo setor social, muito pouco ligado às transformações do mundo urbano, e maior herdeiro de práticas cotidianas de raízes autoritárias e de dependências personalizadas a favor de cúpulas sociais regionais ou produtivas, ia ser um dos fatores que, em médio prazo, incidiriam na reformulação e crise do "modelo modernizador". Assim, a integração democrática estabeleceu em longo prazo a identidade da sociedade uruguaia; porém, seu preço em curto prazo foi uma espécie de "consenso integrador" que implicava o freio à mudança (ibid. 42), assim também como a dificuldade de se pensar alternativas ao modelo. 
Essa situação tornava-se evidente quando aqueles setores sociais e econômicos que haviam recebido certos privilégios e gratificações durante o auge modernizador haviam se acostumado a uma imagem de proteção do Estado, não tendo motivos demasiado evidentes para querer mudá-la. $\mathrm{O}$ que em conclusão havia se produzido era uma "sacralização das instituiçôes” e dos valores sociais que nelas se sustentavam. Assim, os diferentes atores sociais transformaram uma oposição que girava em torno de fins políticos e econômicos em uma oposição baseada nos meios performáticos de funcionamento do sistema político. Sob a operacionalidade das instituiçôes, a vida sociocultural uruguaia deveria e teria de dar solução aos seus desajustes conjunturais. Sem dúvida, radicaram em um acentuado conservadorismo e um excessivo ideal de segurança e certeza, de confiança nas instituições (quase consideradas como possuidoras de vida própria), o eventual fracasso da aventura modernizadora. A um Estado sem projeto lhe corresponderia uma sociedade que concebia o desenvolvimento como um dado externo à sociedade. Isto é,

El ciclo iniciado con el proyecto innovador (modernizador) en que una elite política creó la sociedad desde el Estado, finalizaba con una sociedad que pasaba a controlar el Estado con un conjunto de reivindicaciones particularistas, más propias de la ilusión de la política que de la política misma; controlaba el Estado, en lugar de una elite, una burocracia política que insistía en negociar cuando ya no tenía medios materiales ni simbólicos con que hacerlo. (ibid. 82).

La alta capacidad de sobrevivir, en un largo ciclo de decadencia, de las instituciones y de los valores políticos, de las formas de expresarse culturalmente, y también la continuidad de los estancados y obsoletos mecanismos de producción, ponen de manifiesto la fuerza de la integración nacional. Esta integración llega al límite de maneras de ser, pensar y hacer tan coherentes, que no dejan paso a las tensiones productoras de cambios; en consecuencia, puede hablarse de una sociedad hiperintegrada (ibid. 158).

Se a "baixa institucionalização" nos países latino-americanos supôs a "debilidade do direito", que sugere o "modelo modernizador" com "alta institucionalização" política e social? A sociedade uruguaia, em especial suas classes médias (sua "mesocracia"), seus políticos e intelectuais, sofreram (e sofrem) de uma forte "crise de identidade", diante da qual surgiu 
uma série de respostas: a guerrilha urbana, os movimentos de esquerda política, a "utopia institucionalizadora" e "restauradora" (não sem variantes) do modelo em mãos de alguns militares (o autoritarismo), os renovados movimentos estudantis e sindicais, a deserção cultural, a indiferença política e a emigração.

Não há dúvida de que o caso do Uruguai pode visualizar-se em outras configurações político-institucionais da região. Cada vez que se constatem problemas ante a capacidade e os interesses práticos de um sistema político-institucional que não encontra nada melhor do que tratar de acomodar "novas situaçóes sociais" na antiga normatividade e institucionalidade política, estamos frente a um caso de uma dinâmica histórica da modernidade similar. O desafio parece sempre tentar gerar uma nova normatividade para as emergentes novas situaçóes reais de poder, que no contexto latino-americano fazem referência à decomposição paulatina da cultura política e institucional de várias décadas atrás.

\section{Considerações finais}

A dinâmica da modernidade assume na América Latina uma espécie de princípio de reversibilidade. Nem a "alta" nem a "baixa" institucionalização podem ser consideradas suas premissas constitutivas. Pretende terse em consideração que aquelas "especulações” que se referem ao grau diverso de institucionalização das esferas sociais, políticas e morais como um progressivo movimento de "conquista" em torno de liberdades e garantias de "convivência" não podem adquirir uma validez empírica generalizável. A suposição analítica na direção de "baixa institucionalização" como sinônimo de potencial autoritarismo, desequilíbrios político-morais ou relações sociais sobre a base de diferenças que lesionam identidades subverte as experiências que a posteriori revelam o alto grau de contingência e ambigüidade das sociabilidades. $\mathrm{Na}$ América Latina, a lógica institucional tem revelado, e ainda revela, uma reversibilidade crescente no que diz respeito a regras e códigos de convivência social e mecanismos de negociação espontânea de eventuais problemáticas. Não têm sido os processos de "formalização" de sociabilidades, encarnados em instituições 
reguladoras e ordenadoras, os que têm contribuído para uma garantia mínima de convivência.

Talvez a metáfora das oscilações do "pêndulo da modernidade", tal qual Heller \& Fehér (1994) mencionam, pode ser análoga a essa interpretação. A fantasia de uma marcha constante "para a frente", conquistando aqueles espaços "não legislados", em estado de "ausência de controle", implica algum mecanismo das sociabilidades cuja origem se torna completamente misteriosa. O princípio de reversibilidade nega a validez de uma "mecânica social", de uma dinâmica linear dos acontecimentos. Sendo assim,

[...] en cuanto la modernidad ha alcanzado su forma adecuada al menos en el arte de gobernar, las energías humanas no albergan necesariamente la intención de presionar constantemente "hacia adelante" ni de negociar una trascendencia absoluta. (ibid. 156)

Não se trata de outra coisa além de questionar uma forma de interpretar a realidade social latino-americana que se baseia na possibilidade de compreender e "legislar" aprioristicamente, de oferecer coerência às práticas sociais e racionalidade às ações. Isso é assim porque toda sociologia que outorga centralidade à institucionalização, na América Latina, só compreende e considera objetos de seu estudo sociabilidades que se enquadrariam em esquemas de ação institucionalizados, "sob controle", definíveis como "racionais" e, por conseqüência, como quantificáveis, previsíveis e transparentes. Dessa maneira, não se pode escapar a outro princípio constitutivo das instituições da modernidade: o princípio de fragilidade, já que cada vez menos elas têm onde fundamentar suas práticas e discursos, nada que não seja provisório, parcial e contingente, nada do que possa tratar de legitimar (e convencer) a partir do "metarrelato" do progresso, da história e do desenvolvimento. 


\section{Notas}

${ }^{1}$ Foucault (1988; 1989; 1992).

${ }^{2}$ Faz-se referência à "teoria da institucionalização" de Berger \& Luckmann (2001, orig. 1966). Os autores argumentam que "A institucionalização ocorre sempre que há uma tipificação recíproca de ações habituais por tipos de atores [...] As instituições, também, pelo simples fato de existirem, controlam a conduta humana estabelecendo padrôes previamente definidos de conduta, que a canalizam em uma direção por oposição às muitas outras direçōes que seriam teoricamente possíveis. É importante acentuar que este caráter controlador é inerente à institucionalização enquanto tal, anterior a quaisquer mecanismos de sançôes especificamente estabelecidos para apoiar uma instituição ou independentes desses mecanismos. Tais mecanismos (cuja soma constitui o que geralmente se chama sistema de controle social) existem evidentemente em muitas instituiçôes e em todas as aglomerações de instituições que chamamos sociedade. [...] Dizer que um segmento da atividade humana foi institucionalizado já é dizer que este segmento da atividade humana foi submetido ao controle social" (p. 79-80).

3 "Max Weber distinguió entre esferas sociales y esferas de valores (porque cada esfera tiene su propia deidad); pero nosotros preferimos el término "instituciones" con objeto de reforzar la idea de que existen varias en la misma esfera, al igual que también existen instituciones a horcajadas de varias esferas, y multifuncionales, y cada una de ellas puede adoptar una independencia relativa respecto a las demás" (Heller \& Fehér, 1994, p. 146).

${ }^{4}$ Percepção historicamente recorrente para referir-se aos frágeis canais institucionais que promovam a liberdade e a justiça social, a democracia e a igualdade.

5 "Por 'orden social fundamental' queremos indicar la estructura constante de, y el mecanismo para, la distribución (ordenación) y redistribución (reordenación) de la libertad y de las oportunidades en la vida junto con el mantenimiento (reproducción) de la unidad social completa" (Heller \& Fehér, 1994, p. 140-141).

${ }^{6}$ Pode-se mencionar o "Facundo de Sarmiento" como um dos discursos da modernidade latino-americana em que enfatiza essa característica. Ver Castillo Durante (2000, p. 163-189).

${ }^{7}$ Somando-se à amplamente difundida figura sociojurídica da corrupção, espécie de reverso do jogo institucionalizador.

${ }^{8}$ O processo de industrialização registrou um "decênio glorioso" entre 1945 e 1955, com uma taxa anual de crescimento de $8,5 \%$. Isso levou a um intenso desenvolvimento da educação e da previdência social, de alta mobilidade social ascendente. O país vivia sob uma auto-admiração desmedida, que os dirigentes políticos transmitiam como um credo da certeza. 


\section{Referências bibliográficas}

BARRÁN, José Pedro. Historia de la sensibilidad en el Uruguay (Tomo I y II). Montevideo: Ed. Banda Oriental, 1990.

BAUMAN, Zigmunt. Ética pós-moderna. São Paulo: Ed. Paulus, 1997.

BAYCE, Rafael. Cultura política uruguaya: desde Battle hasta 1988. Montevideo: Ed. Fondo de Cultura Universitaria, 1989.

BERGER, Peter; LUCKMANN, Thomas. A construção social da realidade. Petrópolis: Ed. Vozes, 2001 [1966].

BORGES, Jorge Luis. Ficciones. Buenos Aires: Ed. Alianza, 1998.

BRÜNNER, José Joaquín. América Latina: cultura y modernidad. México: Ed. Grijalbo, 1992.

. Globalización cultural y posmodernidad. México: Ed. FCE, 1998.

CASTILLO DURANTE, Daniel. Los vertederos de la postmodernidad: literatura, cultura y sociedad en América Latina. Ottawa: Ed. Dovehouse, 2000.

CHAMBERS, Iain. Migración, cultura, identidad. Buenos Aires: Ed. Amorrortu, 1994.

DELEUZE, Gilles. Posdata sobre las sociedades de control. In: FERRER, Christian (comp.). El lenguaje literario. Montevideo: Ed. Nordan, 1991.

EWALD, F. Foucault, a norma e o direito. Lisboa: Ed. Veja, 1993.

FOUCAULT, Michel. El sujeto y el poder. In: Revista Mexicana de Sociología, Unam, n. 3, julio-setiembre, México, 1988.

. Microfisica del poder. Madrid: Ed. La Piqueta, 1992.

GADEA, Carlos A. Acciones colectivas y modernidad global. El movimiento neozapatista. Toluca-México: Ed. Uaem, 2004a.

. América Latina. Movimientos sociales e izquierda política. In: Relaciones, $\mathrm{n}^{\circ}$ 246, Montevideo, $2004 \mathrm{~b}$.

GARCÍA CANCLINI, Néstor. Culturas híbridas. Buenos Aires: Ed. Sudamericana, 1995.

HELLER, Ágnes; FERENC, Fehér. Politicas de la postmodernidad. Barcelona: Ed. Península, 1989.

HOPENHAYN, Martín. El debate post-moderno y la dimensión cultural del desarrollo. In: Quijano, Vega, Casullo, García Canclini (y otros). Imágenes desconocidas. La modernidad en la encrucijada postmoderna. Buenos Aires: Ed. Clacso, 1988.

LARRAÍN, Jorge. La trayectoria latinoamericana a la modernidad. In: Estudios 
Políticos, no 66, Santiago de Chile, 1997.

MANSILLA, H.C.F. Los tortuosos caminos de la modernidad. América Latina entre la tradición y el postmodernismo. La Paz: Ed. Centro Boliviano de Estudios Multidisciplinarios, 1992.

PERELLI, Carina; RIAL, Juan. De mitos y memorias politicas: la represión, el miedo y después... Montevideo: Ed. Banda Oriental, 1986.

PERUZZOTTI, Enrique. Modernización y juridización en América Latina. Hacia una crítica del proceso de desarrollo latinoamericano. In: Metapolítica, vol. 5, no 18, México, 2001.

RAMA, Germán. La democracia en Uruguay. Una perspectiva de interpretación. Buenos Aires: Ed. Grupo Editor Latinoamericano, 1987.

RICHARD, Nelly. Latinoamérica y la posmodernidad. In: Revista La Torre, Universidad de Puerto Rico, no 12, Puerto Rico, 1999.

RINCÓN, Carlos. La no simultaneidad de lo simultáneo. Postmodernidad, globalización y culturas en América Latina. Bogotá: Ed. Universidad Nacional, 1995.

SENNETT, Richard. A cultura do novo capitalismo. Rio de Janeiro: Ed. Record, 2006.

TORO, Alfonso de; TORO, Fernando de. El debate de la postcolonialidad en Latinoamérica. Alemania: Ed. Vervuert, 1999.

WAGNER, Peter. Sociología de la modernidad. Barcelona: Ed. Herder, 1997.

\section{RESUMO}

O presente trabalho pretende delinear alguns traços significativos do que se poderia compreender como modernidade na América Latina. O interesse radica em discutir como a caracterização da particular experiência histórica da modernidade latinoamericana requer de uma interpretação do sentido e significado dos processos de institucionalização de sociabilidades, disciplinamento e uniformidade cultural. Uma análise da modernidade na América Latina sugere destacar aqueles dispositivos normativos que fazem referência à formalização e institucionalização de experiências sociais. Assim, pretende-se argumentar que as múltiplas práticas modernizadoras parecem ter apresentado uma ambigua lógica institucionalizadora: caracterizam-se por seus marcados signos de fragilidade e ausência em determinadas esferas da vida social, ao mesmo tempo em que denotam uma forte presença homogeneizadora e disciplinar, materializadas em uma instituição, o Estado, que conseguiu se situar acima das demais.

Palavras-chave: modernidade, América Latina, sociabilidade, institucionalização. 


\section{ABSTRACT}

The present article intends to describe some significant traces of what could be understood as modernity in Latin America. Such an interest involves the discussion on how the characterization of a particular historic experience of Latin American modernity requires an interpretation of the sense and meaning of the process of institutionalization of sociabilities and cultural disciplination and uniformity. An analysis of modernity in Latin America suggests a focus on those normative mechanisms which refer to the formalization and institutionalization of social experiences. So, one intends to observe that multiple modernizing practices seem to have shown an ambiguous institutionalizing logic: on the one hand, they are characterized by clear signs of fragility along with absence in certain fields of social life, at the same time in which they denote a strong homogenizing and disciplining presence, materialized into an institution, the State, which happens to lie above all the others.

Keywords: modernity, sociabilities, institutionalization, Latin America.

Recebido em dezembro de 2006 e aprovado em outubro de 2007 